MATEC Web of Conferences 13, 04005 (2014)

DOI: $10.1051 /$ matecconf/ 20141304005

(C) Owned by the authors, published by EDP Sciences, 2014

\title{
Extraction of Continuous Fiber from Mengkuang Leaves: The Influence of Process Parameters during Alkaline Treatment
}

\author{
Muhammad Syahmi Hamizol ${ }^{1, \text { a }}$,Puteri Sri Melor Binti MegatYusoff ${ }^{1, \text { b }}$, and Muhamad Ridzuan Bin \\ Abdul Latif ${ }^{2, c}$ \\ ${ }^{1}$ Mechanical Engineering Department, Universiti Teknologi PETRONAS, Tronoh, Malaysia \\ ${ }^{2}$ Research and Publication Secrerariat, Faculty of Islamic Studies, Universiti Kebangsaan Malaysia, \\ Bangi, Malaysia
}

\begin{abstract}
Currently, natural cellulose fiber composite is a promising prospect in the composite world. However, achieving uniform strength in natural fiber composite is a challenge due to limited fiber length and its random orientation in the composite. Thus, the focus of this paper was to obtain a continuous cellulose fiber from mengkuang leaves using chemical extraction process. The chemical extraction involved alkaline treatment of the mengkuang leave followed by bleaching. This paper focused on extraction using sodium hydroxide $(\mathrm{NaOH})$ and its process parameters. The process parameters of the extraction were varied in terms of concentration of $\mathrm{NaOH}$ solution and also the soaking time. The texture and structure of the chemically purified continuous cellulose fiber were observed by visual inspection. Detailed microstructural analysis was carried out using Field Emission Scanning Electron Microscopy (FESEM) while chemical composition analysis in term of cellulose percentage was conducted using Technical Association of the Pulp and Paper Industry (TAPPI); TAPPI T203. Preliminary results showed that increment in cellulose percentage when the concentration of $\mathrm{NaOH}$ and soaking time were increased.
\end{abstract}

\section{Introduction}

Natural fiber is widely used in automobile and household industries such as materials for interior of passenger cars, truck cabins, furniture and as thermo-acoustic insulation material [1]. Due to various advantages of natural fibers such as biodegradability, sustainability and abundance, numerous research have been conducted on natural fibers, such as wood fibers [2], cotton [3], hemp [4] and many others, to explore their potential in the development of new materials. Several works had been carried out including works based on mengkuang leaf (pandanustectorius) [5] which is widely available in Malaysia. Mengkuang leaf possesses high strength which makes it suitable for making rope, hats and mats [6].The strength of natural fibers is directly related to their cellulose content [7] and mengkuang leaves have shown to exhibit high cellulose content [6]. However, the cellulose needs to be extracted in the form of long fiber before it can be incorporated into other matrix materials to produce composite materials with high strength for potential use in the automotive, construction, manufacturing and other industries.

\footnotetext{
aspikiez89@gmail.com, ${ }^{\mathrm{b}}$ puteris@petronas.com.my, ${ }^{\mathrm{c}}$ ridzual@gmail.com
} 
Up to date, various extraction methods have been reported. There are, mechanical treatment which involves grinding [2], chemical treatment [8], biological treatment involving enzyme-assisted hydrolysis [9] as well as combination of two or more of the aforementioned methods. Most of the treatments used highly aggressive hydrolysis and/or shearing force during fibrillation which often resulted in short fiber length of the cellulose obtained [10]. Thus, this is undesirable. In order to exploit the full potential of natural fiber, it is a must to obtain continuous fiber, since the reinforcement effect of a continuous fiber is higher compared to that of short and discontinuous [11].Moreover, natural fiber composite manufacturers are faced with difficulties to fabricate a high and uniform strength composite due to the random orientation of short fibers [12]. The strength of fiber-filled composites is influenced by various factors including content, orientation and length of the fiber [11-12]. Generally, longer fiber length is favored as it improves the composite's tensile strength. However, there have been several works attempted to reduce the filler to nano size. They attempted to study the effect of nano size fiber on composite's tensile strength. [5, 13-14].

In this study the effects of extraction parameters in obtaining continuous and high level cellulose fiber content from mengkuang leaf were investigated..

\section{Experimental}

\subsection{Material}

Mengkuang leaves were obtained in the form of mengkuang mat locally. The chemical reagents used were supplied by Avantis Laboratory such sodium hydroxide and sodium chlorite.

\subsection{Extraction of Cellulose}

Mengkuang mat was washed thoroughly with distilled water and dried under the sun. It was cut into $12 \mathrm{~cm}$ long and $3 \mathrm{~cm}$ wide strips and weighed accordingly. Each strip was approximately $0.3-0.35$ grams. The leaves were treated with $2 \%$ up to $10 \%$ of $\mathrm{NaOH}$ at $200^{\circ} \mathrm{C}$ for 60 and 120 minutes. The ratio of the leaves to liquor was $5: 300(\mathrm{~g} / \mathrm{ml})$. The leaves were washed with distilled water after each treatment and were dried under the sun for 3 days.

\subsection{Characterization}

Visual inspection of the mengkuang leaves in terms of structure and texture was carried out after each alkaline treatment. Inspection was conducted after the strips were washed with distilled water and sun dried.The fiber microstructure, before and after treatment was observed using Zeiss SUPRA55VP with an accelerating voltage of $3 \mathrm{kV}$. The images were digitally recorded. The percentage of cellulose fiber were determined by using TAPPI standard; T203. $25 \mathrm{~mL}$ treated mengkuang solutions were added with $10.0 \mathrm{~mL}$ of $0.5 \mathrm{~N}$ potassium dichromate solution. $50 \mathrm{~mL}$ of concentrated $\mathrm{H} 2 \mathrm{SO} 4$ was added cautiously followed by $50 \mathrm{~mL}$ of water after 15 minutes. 2 to 4 drop of Ferroin indicator was then added and titrated with $0.1 \mathrm{~N}$ ferrous ammonium sulfate solution to a purple color

\section{Results}

\subsection{Physical Observation}

Fig 1(a) shows the initial condition of the mengkuang leaves which was brownish in color. Alkaline treatment gave a significant effect on the mengkuang leaves texture and structure. Upon alkaline 


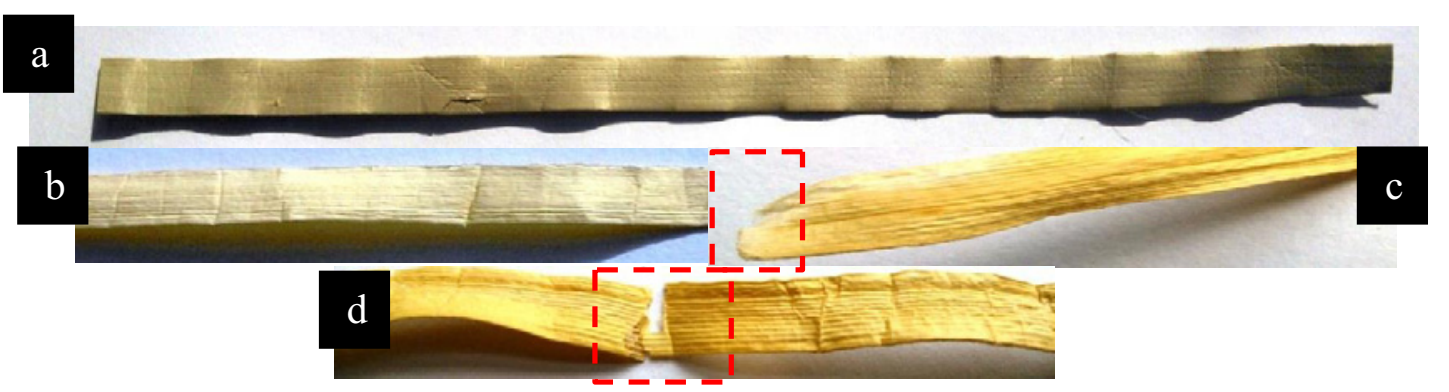

Figure 1. Visual inspection of the mengkuang leaf strips before and after each extraction process: (a) Mengkuang mat, (b) Alkaline treatment at $6 \% \mathrm{NaOH}$ for 90 minutes (c) Alkaline treatment at $8 \% \mathrm{NaOH}$ for 90 minutes, (d) Alkaline treatment at $10 \% \mathrm{NaOH}$ for 60 minutes.

treatment of $2-6 \% \mathrm{NaOH}$, the brownish color started to fade, as seen in Fig. 1(b) and (c). However, after $10 \% \mathrm{NaOH}$ treatment of $60 \mathrm{~min}$ of the leave, the brownish color started to darken when the leave was treated with $7-10 \%$ of $\mathrm{NaOH}$. As demonstrated in Fig. 1(d), the leaves became more brittle after being treated and dried under the sun. Meanwhile, the longer the soaking time during treatment, the more extensive the reaction and the more substances were extracted or removed. Although higher concentration of $\mathrm{NaOH}$ would be more effective in extracting the lignin and hemicellulose components of the mengkuang leaves, the use of highly concentrated solutions could cause defects on the leaves. Similar observations were found on sugar palm which demonstrated poor mechanical properties due to increase in concentration during chemical treatment [15]. As shown in Fig. 1(c), signs of degradation or decay were observed at the end of the leaf after being treated with $6 \%$ of $\mathrm{NaOH}$ for 90 minutes soaking time. Moreover, continuous fiber was obtained extracted of succesfully if the concentration of $\mathrm{NaOH}$ was keep less than $7 \%$ with soaking time less 90 min.
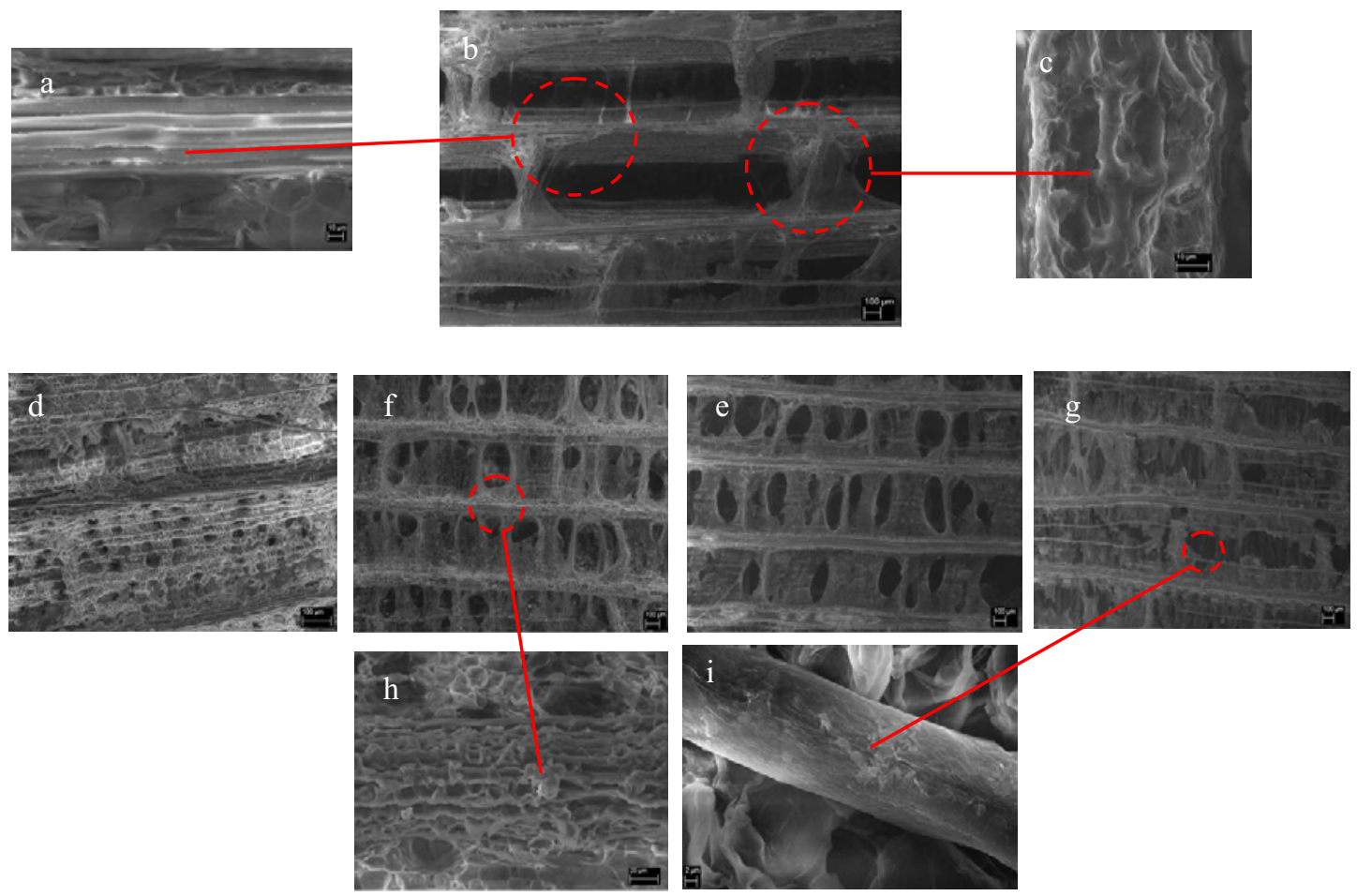

Figure 2. FESEM micrographs of mengkuang leaves: (a) Lines of microfibrils from mengkuang mat, (b) Microfibril structure of mengkuang mat, (c) Hemicellulose and lignin structure of mengkuang mat, (d) Alkaline treatment at $2 \% \mathrm{NaOH}$ for 60 minutes, (e) Alkaline at $2 \% \mathrm{NaOH}$ for 90 minutes (f) Alkaline treatment at $6 \%$ $\mathrm{NaOH}$ for 60 minutes (g) Alkaline treatment at $6 \%$ for 90 minutes (h) single fiber after alkaline treatment at $2 \%$ $\mathrm{NaOH}$ for 90 minutes (i) single fiber after bleaching at $6 \%$ for 90 minutes 


\subsection{Morphological Analysis}

Fig. 2 show microscopic examination of the mengkuang leaves. The examination mainly focused on longitudinal cross section of the leaves at different stage of extraction process; before treatment and after alkaline and bleaching treatments. Fig. 2(a) shows the micrograph of the original mengkuang leaves as taken from the mengkuang mat. It clearly shows lines of microfibrils bonded by hemicelluloses and lignin Fig 2(b). The microfibrils structure resembled regular, hollow rectangular. Each microfibrils consists of several cellulose fiber measuring $10-15 \mu \mathrm{m}$ wide in diameter. The microfibrils were bundled up together by lignin which were then connected by 'bridges' between one layer of microfibrils to another forming shape of the rectangular cell structureas in Fig 2(c). The 'bridges' created a partition in the mengkuang leaf microstructure. Fig 2(d), (e), (g) and (i) show, SEM images of the mengkuang leaves after alkaline treatment at varying $\mathrm{NaOH}$ concentration. Hemicellulose and lignin were still present in the microfibrills after being treated with $2 \% \mathrm{NaOH}$ for 60 minutes. The conditions were insufficient to remove all of the hemicellulose. However, as the concentration of $\mathrm{NaOH}$ was increased to $6 \%$, while maintaining the soaking time at 60 minutes, more voids in the microfibril structure were observed. Similar characteristics were observed after treatment at $2 \% \mathrm{NaOH}$ but with prolonged soaking time of 90 minutes. The reduction in hemicellose content was further observed as $\mathrm{NaOH}$ concentration was increased to $6 \%$ with soaking time of 90 minutes as demonstrated in Fig 2(i). Voids were bigger and the partition in structure was reduced. The microstructural observations showed that the alkaline treatment as extracted or removed the hemicellose content of the leaves. However, the microfibrils were still intact due to the presence of lignin layer as in Fig. 2(h)

\subsection{Chemical Composition Analysis}

A normal mengkuang leaf possess $37.3 \%$ of cellulose contains [5].Table 1, shows the extracted cellulose percentage measured as the concentration and soaking time of $\mathrm{NaOH}$ increased. The data were plotted for linear regression analysis as shown in Fig. 3. Linear regression analysis led to Eq. 1 and Eq. 2 which can be used to model the relationship between $\mathrm{NaOH}$ concentration, $x$ and cellulose percentage, $y$ at $120 \mathrm{~min}$ and $60 \mathrm{~min}$ of soaking time, respectively;

$$
\begin{aligned}
& y=2.34 x+47.58 ; R^{2}=0.981 \\
& y=3.18 x+35.42 ; R^{2}=0.896
\end{aligned}
$$

The slope of the 60 minute-soaking time is steeper than that for 120 minutes. This indicates that concentration of $\mathrm{NaOH}$ has greater influence on the extracted cellulose percentage at a lower soaking time. However, the amount of cellulose extracted is less than that obtained during 120 minutes

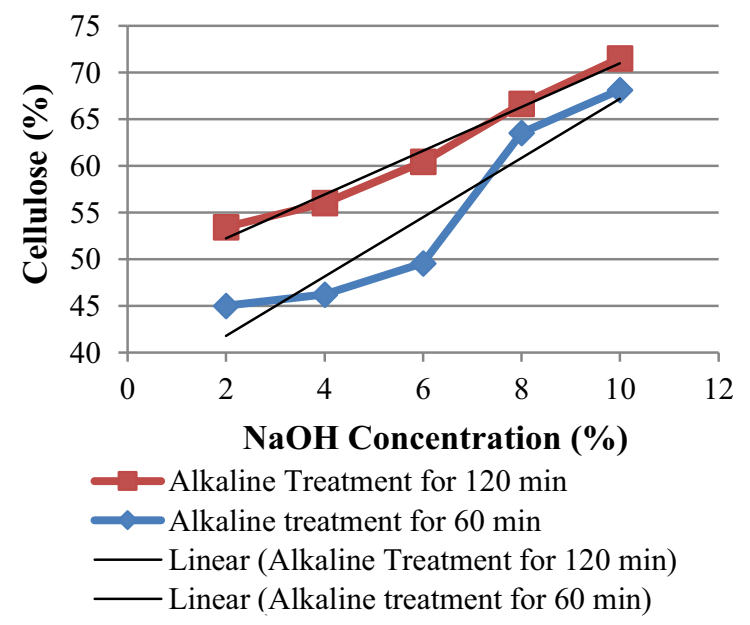

Table 1. The Percentage of Cellulose Fiber

\begin{tabular}{|c|c|c|}
\hline $\begin{array}{c}\text { Alkaline Treatment } \\
\text { Concentration } \\
{[\%]}\end{array}$ & $\begin{array}{c}\text { Soaking } \\
\text { Time } \\
{[\mathrm{min}]}\end{array}$ & $\begin{array}{c}\text { Cellulose } \\
\text { Contain } \\
{[\%]}\end{array}$ \\
\hline 2 & 60 & 45.0121 \\
\hline 2 & 120 & 53.4523 \\
\hline 4 & 60 & 46.2342 \\
\hline 4 & 120 & 56.0213 \\
\hline 6 & 60 & 49.5623 \\
\hline 6 & 120 & 60.4531 \\
\hline 8 & 60 & 63.5432 \\
\hline 8 & 120 & 66.6534 \\
\hline 10 & 60 & 68.1398 \\
\hline 10 & 120 & 71.5432 \\
\hline
\end{tabular}

Figure 3. Linear Regression Analysis 
soaking time at all $\mathrm{NaOH}$ concentration studied. Also, it is noted that Eq. 1 has higher coefficient of determination, $\mathrm{R}^{2}$ of 0.981 (120 mins) compared to that obtained for Eq. 2 of 0.896 (60 mins). In other words, the amount of extracted cellulose content at 120 minutes soaking time is better replicated by the model compared to that at 60 minutes.

\section{Conclusions}

The $\mathrm{NaOH}$ extraction process under investigation was able to extract continuous cellulose fiber from the mengkuang leaves. It was found that higher $\mathrm{NaOH}$ concentration and longer soaking time, employed during the treatment, resulted in increased amount of cellulose extracted. For the same $\mathrm{NaOH}$ concentration applied, higher cellulose content was extracted at 120 minutes compared to 60 minutes soaking time. It was observed that the alkaline concentration had a greater influence on the amount of cellulose extracted at a higher soaking time.

\section{References}

1. T. Schuh, U. Gayer, in A.L. Leao, F.X. Carvallo, E. Frollini (eds), Lignocellulosic Plastic Composites, UNSEP, Sao Paolo, 181 (1997)

2. Abe, K., Iwamoto, S.,\&Yano, H. Obtaining cellulose nanofibers with a uniform width of $15 \mathrm{~nm}$ from wood. Biomacromolecules, 8(10), 3276-3278 (2007)

3. De Morais Teixeira, E., Correa, A., Manzoli, A., de Lima Leite, F., de Oliveira, C., \&Mattoso, L. Cellulose nanofibers from white and naturally colored cotton fibers.Cellulose, 17(3), 595-606. (2010)

4. Wang, B., Sain, M., \&Oksman, K. (2007). Study of structural morphology of hemp fiber from the micro to the nanoscale.Applied Composite Materials, 14(2), 89 - 103 (2007)

5. R. M. Sheltami, I. Abdullah, I. Ahmad, A. Dufresne, and H. Kargarzadeh, "Extraction of cellulose nanocrystals from mengkuangleaves (Pandanus tectorius)," Carbohydrate Polymers, 88,772-779 (2012)

6. Giesen, W., Wulffraat, S., Zieren, M., \&Scholten, L. Mangrove guidebook for Southeast Asia, (part II). The Netherlands: FAO and Wetlands International (2006/07)

7. A. K. Bledzki and J. Gassan, "Composites reinforced with cellulose based fibres," Progress in Polymer Science, 24,221-274 (1999)

8. Araki, J., M. Wada, S. Kuga, and T. Okano, Birefringent glassy phase of a cellulose microcrystal suspension. Langmuir, 16, 3298-3305 (2000)

9. Hayashi N, Kondo T, Ishihara M, Enzymatically produced nano-ordered shorts containing cellulose I_crystalline domains. Carbohydr, 61, 191-197 (2000)

10. W. Chen, H. Yu, and Y. Liu, "Preparation of millimeter-long cellulose I nanofibers with diameters of 30-80 nm from bamboo fibers," Carbohydrate Polymers, 86, 453-461 (2011)

11. S. K. Garkhail, R. W. H. Heijenrath, and T. Peijs, "Mechanical properties of natural-fibre-matreinforced thermoplastics based on flax fibers and polypropylene," in Applied Composite Materials, 7, 351-372 (2000)

12. J. Gassan, "A study of fibre and interface parameters affecting the fatigue behaviour of natural fibre composites," Composites Part A: Applied Science and Manufacturing, 33, 369-374 (2002).

13. G. Gong, J. Pyo, A. P. Mathew, and K. Oksman, "Tensile behavior, morphology and viscoelastic analysis of cellulose nanofiber-reinforced (CNF) polyvinyl acetate (PVAc)," Composites Part A: Applied Science and Manufacturing, 42, 1275-1282 (2011)

14. R. Masoodi, R. F. El-Hajjar, K. M. Pillai, and R. Sabo, "Mechanical characterization of cellulose nanofiber and bio-based epoxy composite," Materials \& Design, 36, 570-576 (2012)

15. M. R. Ishak, S. M. Sapuan, Z. Leman, M. Z. A. Rahman, U. M. K. Anwar, and J. P. Siregar, "Sugar palm (Arenga pinnata): Its fibres, polymers and composites," Carbohydrate Polymers, 91, 699-710 (2013) 